\title{
EI traductor de textos no literarios en los siglos XVIII y XIX: enciclopedista, innovador y mediador
}

\author{
Gerda Haßler \\ Universität Potsdam \\ hassler@uni-potsdam.de
}

\begin{abstract}
Resumen: Las traducciones de textos científicos jugaban un papel importante en el desarrollo de las ciencias en España en la segunda mitad del siglo XVIII y en la primera del siglo XIX. Nos concentraremos en los traductores que contribuyeron a la difusión del saber científico como la publicación de la traducción de la Enciclopedia Metódica a partir de 1788,cuyo objetivo fue promover el desarrollo de España, especialmente en el aspecto económico. Los textos franceses sobre química eran otro objeto muy frecuente de traducción, por ejemplo, la Memoria sobre la necesidad de perfeccionar y reformar la nomenclatura de la química (1787) de Lavoisier. Los traductores buscaban soluciones traductológicas que se adaptasen mejor al genio de la lengua española y se entendían como enciclopedistas, innovadores y mediadores.
\end{abstract}

Palabras clave: terminología; traducción; adaptación; analogía; denominación.

\section{The translator of non-literary texts in the 18th and 19th centuries: en- cyclopedists, innovators and transmitters of knowledge}

\begin{abstract}
Translations of scientific texts played an important role in the development of the sciences in Spain during the second half of the 18th and the first half of the 19th century. We will concentrate on translators that contributed to the spreading of scientific knowledge. A prominent example here is the progressive publication of the translation of the Encyclopédie méthodique from 1788, undertaken with the goal of advancing in particular Spain's development in economic matters. French chemistry texts were also frequently translated, such as Lavoisier's Mémoire sur la nécessité de réformer et de perfectionner la nomenclature de la chimie (1787). The translators also discussed the best solutions for making translations suited to the genius of the Spanish language and they saw themselves as encyclopaedists, innovators and transmitters of knowledge.
\end{abstract} Keywords: terminology; translation; adaptation; analogy; denomination. 



\section{Características de la época y de su pensamiento}

La España del siglo XVIII ha sido estudiada desde el punto de vista de un nuevo inicio y de la ruptura con la tradición. Que esta tendencia dominante no haya sido propicia a los representantes de la Ilustración española se puede confirmar con varios documentos. Para la imagen de la ilustración distribuida en el siglo XIX, me parece interesante lo que dice Marcelino Menéndez y Pelayo (1856-1912) en su Historia de los heterodoxos españoles [1880]:

Quien busque ciencia seria en la España del siglo XVIII tiene que buscarla en esos frailes ramplones y olvidados. Más vigor de pensamiento, más clara comprensión de los problemas sociales, más lógica amartilladora e irresistible hay en cualquiera de las cartas del filósofo Rancio, a pesar del estilo culinario, grotesco y de mal tono con que suelen estar escritas, que en todas las discusiones de las Constituyentes de Cádiz o en los raquíticos tratados de ideología y derecho público, copias de Destutt de Tracy o plagios de Bentham, con que nutrió su espíritu la primera generación revolucionaria española, sin que aprendiesen otra cosa ninguna en más de cuarenta años (Menéndez y Pelayo, 1963 [1880]: $363)$.

La invasión francesa había puesto el fundamento de una leyenda que Javier Herrero (1973) llama el mito reaccionario. Lo caracteriza como expresión irracional del pensamiento antiilustrado que apela a las pasiones de los grupos de la población que no están satisfechas por las inquietudes de la razón y de la libertad. La estructura fundamental de este mito consiste en la oposición de las fuerzas del mal y del bien, las del pecado conspirando contra el bien. Mientras que el bien siempre está relacionado con la tradición, para la conspiración del mal se da la enumeración linear de los filósofos, los jansenistas y los francmasones. Se construye un sistema de sinónimos que simplifica el contenido nocional y establece relaciones de equivalencia entre conceptos muy diferentes. Así por ejemplo, Fernando Ceballos (1732-1802) dice en su Falsa filosofia: "En este último estado son llamados deístas, o libertinos, o indiferentes, o filósofos. Todas estas voces son sinónimas" (Ceballos, 1774-1776: I, 12).

En estos contextos la lengua cumple un papel importante como medio de comunicación así como sujeto de la discusión. Se plantea el pro- 
blema del lenguaje como asunto de discusiones filosóficas que tienen lugar en los últimos años del siglo XVIII y al inicio del siglo XIX.

La construcción de paradigmas de sinónimos que hemos visto en el ejemplo de Ceballos tiene sus paralelas en textos ilustrados que se encuentran en relación con los ideólogos franceses. Los propagadores de la ideología en España se consideraron a sí mismos iniciadores de un modo de pensar y sus textos debían ser -según su intención- textos de referencia para una nueva tradición. Una traducción española de los Elementos de ideología de Antoine Louis Claude Destutt de Tracy (1754-1836) está introducida por las siguientes palabras:

Contra las sombras es menester la luz: contra las falsas luces otras luces mayores. Pero apagar todas las luces, o, lo que es lo mismo, proscribir una ciencia entera, y quedarse en tinieblas, es dar más fuerza a las ilusiones, y acrecentar sus progresos y sus influencias (Destutt de Tracy, 1826: 24).

No se trata aquí de un simple juego de metáforas que comparan la luz con el saber y la razón humana, las tinieblas con la superstición y las ilusiones. Se plantea, por el contrario, el problema de la continuidad del pensamiento de la Ilustración que en los escritos españoles antiilustrados se identifica con el nombre de la falsa filosofia.

En la España del siglo XVIII, el sensualismo es el movimiento filosófico que más se acerca al nuevo espíritu de los tiempos (Abellán, 1981: 512). Se trata de encontrar un fundamento teórico que haga posible la fundación de la ciencia natural y la explicación de los principios por la realidad de lo dado, y no la realidad por los principios. La fundación y la denominación de ideas complejas no son para los sensualistas obra de la naturaleza sino que dependen de una imposición voluntaria, que funda su carácter arbitrario y particular de cada lengua.

La recepción del sensualismo en España empieza con su versión lockiana, a cuya difusión contribuyó el Verdadero método de estudiar para ser útil a la República y a la Iglesia de Verney, que apareció en lengua portuguesa en 1746 (Verney, 1746) y en versión castellana del doctor en teología y leyes, abogado de los Reales Consejos Joseph Maymò y Ribes (Verney, 1760), quien publicó también una defensa de su autor (Maymò y Ribes, 1758). En El verdadero método el ataque a la tradición se hace sobre la base de una nueva postura ante el problema del conocimiento, en especial, en lo que se refiere al origen de las ideas. 
Mediante sus traducciones de la lógica de Condillac (1784a, 1794) Bernardo Maria de Calzada (1751-1825) y Valentín de Foronda (17511821) pasan por ser unos de los más eficaces difusores del sensualismo. En el prólogo de la obra, Foronda hace constar que había traducido y adaptado la Lógica de Condillac en forma de diálogo a fin de educar a su hijo en ella. La figura central del movimiento ilustrado en España, Gaspar Melchor de Jovellanos (1744-1811), profesa una lógica sensualista en la que se identifican las ideas con las palabras, y dice:

No olviden jamás que en esta exacta correspondencia de los signos con las ideas consiste el verdadero saber, porque la verdad no es otra cosa que la conveniencia de los hechos o percepciones con lo que afirmamos de ellas; que no por otra razón se llaman exactas las ciencias matemáticas, que porque en su nomenclatura hay esta exacta conveniencia entre las palabras y las ideas, y en fin, que éste es el único camino de elevar las ciencias intelectuales a la clase de demostrativos (Jovellanos, 1963: 250).

Se impone aquí la idea de Condillac de que el arte de pensar ha coincidido de tal manera con el arte de hablar que vienen a ser virtualmente lo mismo. Con esta idea inició su Lengua de los cálculos, publicada póstumamente en 1798 y la versión española en 1805 (Condillac, 1805). Si una ciencia no es otra cosa que una lengua bien construida, lo primero que debe hacer un pensador riguroso es determinar el sentido de las palabras con que se representan las ideas.

Instituciones importantes para las actividades de traducción en España fueron las Sociedades económicas de amigos del país que surgieron en la segunda mitad del siglo XVIII. Nacieron en el reinado de Carlos III, quien las puso bajo la protección real para que fueran un instrumento del reformismo borbónico y de la difusión de las nuevas ideas y conocimientos científicos y técnicos de la Ilustración. La primera Sociedad de amigos del país fue la Sociedad Bascongada, fundada en 1764 y aprobada por el Consejo de Castilla en 1772. Los fines de esta sociedad eran ampliar los nuevos conocimientos científicos hacia las actividades económicas, por ejemplo en las ferrerías. Además enseñaban aquellas materias que no se explicaban en las universidades, como la física experimental o la mineralogía, y establecieron cátedras de historia y de francés. 
Por iniciativa del fiscal del Consejo de Castilla, Pedro Rodríguez de Campomanes (1723-1802), el ejemplo de la Bascongada se extendió a todo el reino y se constituyeron más de sesenta Sociedades de Amigos del País por toda España entre 1775 y finales del reinado de Carlos III. El proyecto expuesto por Campomanes en el Discurso sobre el fomento de la industria popular (1774) y en el Discurso sobre la educación popular y su fomento (1775) y realizado en la Sociedad Económica Matritense de Amigos del País, fundada en 1775, era que la iniciativa partía del Gobierno, con lo que la existencia de un grupo de ilustrados no era una condición previa para su fundación. Su función fundamental era apoyar las reformas emprendidas por los ministros del rey, lo que aumentaba considerablemente la tutela pública sobre estas. El acceso a las sociedades quedaba restringido a la nobleza más ilustrada, caballeros, eclesiásticos y gentes ricas, y miembros de la administración y autoridades locales. Su ámbito de actividades se restringía a la teoría y práctica de la economía política en todas las provincias de España, por lo que se prescindía de la "Historia, Política y Buenas Letras" y pasaban a un segundo plano las matemáticas, la física y la medicina.

\section{Traductores como enciclopedistas y el enciclopedismo en España}

Ya la Sociedad Bascongada de Amigos del País logró formar una importante biblioteca y consiguió el permiso para suscribirse a la Enciclopedia francesa, aunque con la condición de que sólo pudiera ser consultada por los socios de la entidad que tuvieran licencia de la Inquisición para leer libros prohibidos. Esta condición, al parecer, no se cumplió. El moralista antiilustrado Ceballos denunció que en las sociedades se hablaba con peligrosos aires republicanos y que algunas hubieran conseguido la licencia de leer libros prohibidos con el consiguiente peligro de introducir ideas subversivas. Es seguro que eso era una exageración. Estas sociedades se convirtieron en uno de los productos más representativos del idealismo de una minoría de ilustrados. Su concepción de la sociedad todavía unía la felicidad pública a la desigualdad jurídica y a la monarquía absoluta.

La Enciclopedia francesa fue, sin embargo, una de las grandes obras que contribuyeron a la difusión del saber moderno en España, pero su contenido era solamente accesible a las personas que poseían la len- 
gua francesa. Tampoco se olvidaban las críticas que se dirigieron a esta obra y a sus protagonistas, que dieron un sentido muy peyorativo a las palabras enciclopedismo y enciclopedistas. A partir de 1788 empezó la publicación de la traducción de la Enciclopedia Metódica con el fin de promover el desarrollo de España, especialmente en el aspecto económico, desarrollo que se inició en los círculos culturales. Pero el contenido de la Enciclopedia Metódica era diferente al de la Gran Enciclopedia francesa, publicada por Denis Diderot (1713-1784) y Jean-Baptiste le Rond d'Alembert (1751-1772). Se había cortado la inquietud intelectual de la Enciclopedia, que se puede considerar revolucionaria, quedando una obra que reúne todos los conocimientos de muchas áreas del saber. Esta compilación podía ser muy útil también para la formación de jóvenes burgueses. Es por esta razón, meramente económica, y para facilitar el acceso a ella, por lo que emprendieron una traducción en España; pero no del diccionario enciclopédico en su orden alfabético, sino de la Enciclopedia Metódica ordenada según disciplinas y campos de conocimientos. Mientras que en algunos de ellos, por ejemplo, el arte militar, la geografía moderna y las fábricas, artes y oficios (véase Enciclopedia Metódica 1791b, 1792a, 1792b, 1794), la traducción resultó ser un gran éxito, los esfuerzos fueron menos provechosos en sectores no ligados a la economía.

A pesar de ser un diccionario de las cosas, se atribuye mucha atención a las palabras en la redacción de la Enciclopedia Metódica. Esto también se puede observar en la parte sobre la Historia natural de los animales, donde se critica la introducción de muchos sinónimos que designan el mismo concepto. Según el autor de la introducción se trata de un abuso que debe ser combatido:

Hay varias dificultades en el estudio de la Historia Natural, que haciendola fastidiosa, inspiran algun disgusto á los que se dedican á esta ciencia. Estas dificultades no se encuentran en la Naturaleza, provienen de los abusos que la mayor parte de los Autores Naturalistas han introducido en sus escritos: la mayor falta en que han caido, es la multitud de nombres que han dado á una misma cosa; de donde ha resultado un inconveniente todavia mayor en las denominaciones vanas y quimericas, que no tienen objeto real. Quando se dan muchos nombres á una misma cosa, se presenta un atractivo engañoso á los principiantes en la Historia Natural; les parece que quantos mas nombres tenga la cosa, mejor la podrán conocer (Historia natural: Enciclopedia metódica, 1788b: V). 
Veremos que este debate sobre los sinónimos, también en el Diccionario de Gramática y literatura, conduce a reflexiones, pero más diferenciadas y con menos hostilidad contra los sinónimos. La fuerza cognitiva del lenguaje, que se niega claramente en la introducción de la Historia Natural, es una idea que viene a ser discutida también en España a finales del siglo XVIII.

En esta situación, una traducción de la Enciclopedia metódica era bienvenida en España también con fines pedagógicos. Dice el traductor Luis Miguel de S. Fernando del Orden de Escuelas Pías en el prefacio a su obra:

[...] esta obra, para decirlo assi, es el alma ó quinta esencia de todos los grandes hombres juntos, dispuesta con el debido orden para formar con ella otros semejantes en todos los generos de buenas letras, en que aquellos sobresalieron. Y por esta razon puede considerarse como un Plan de educacion nacional en el ramo de Buenas Letras absolutamente necesario, y por el que pueden guiarse con seguridad los Jovenes, y toda clase de Escritores. Se le puede mirar como una de aquellas Obras clasicas, que hacen ley en punto de Literatura (Diccionario de gramática y literatura: Enciclopedia metódica, 1788a: II).

Con estas palabras había intentado integrar el Diccionario de gramática y literatura en las autoridades que debían observarse para el buen uso por sus soluciones terminológicas y por los textos presentados en ello. Se manifiesta muy claramente que la terminología en los ámbitos de las ciencias sociales o de las producciones del espíritu humano no es técnica en el sentido estricto y siempre depende de opiniones y puntos de vista.

Los traductores de la Enciclopedia metódica no se limitan a la traducción del francés al castellano (en la cual solucionan muchos problemas terminológicos), sino que presentan un diccionario ilustrado $y$ aumentado, aportando adiciones en la traducción española.

En el tomo primero de la historia natural de los animales, traducido por Gregorio Manuel Sanz y Charias, se encuentra un Suplemento a los animales cuadrúpedos en el cual se explican las palabras siguientes:

CHILIHUEQUe (el) llamado propiamente hueque, pero los Araucanos, que lo tienen doméstico, empezaron á denominarle desde el arribo de los Españoles Chilihueque, ó Rehueque, que quiere decir Hueque Chileño, o Hueque puramente, para distinguirlo del carnero europeo, al 
qual dan el propio nombre por la semejanza que tienen uno con otro. [...] (Enciclopedia metódica, 1788b: 295).

CHINCHIMEN, ó gato marino (el), es un animalejo que tendrá veinte pulgadas de largo, midiendo desde la punta del hocico hasta el origen de la cola [...] (Enciclopedia metódica, 1788b: 295).

ChINGUE, en el reyno de Chile es el Zorrillo (Enciclopedia metódica, 1788b: 296).

CHINO, (perro) casta de perros originarios de los paises cálidos, y cuya piel está casi desnuda de pelo (Enciclopedia metódica, 1788b: 296).

COLOCOLO, (el) es un gato montés mayor que el doméstico, y semejante á él en su forma y su pelo [...] (Enciclopedia metódica, 1788b: 296). COYPU, (el) es un topo aquatico del tamaño de la nutria [...] (Enciclopedia metódica, 1788b: 296).

CULPEU (el), es un perro montaráz, ó mas bien una zorra grande que solo se distingue de la comun en la magnitud [...] (Enciclopedia metódica, 1788b: 296).

CUY, (el) es una especie de conejo pequeño, [...] (Enciclopedia metódica, 1788b: 296).

DEGU, es una especie de liron algo mas grande que las mayores ratas caseras, [...] (Enciclopedia metódica, 1788b: 297).

GUANQUE (el). Es un topo semejante á el campestre en figura y tamaño; pero cuyas orejas son mas redondas [...] (Enciclopedia metódica, 1788b: 297).

GUINA (la) es un gato montés, que habita en los bosques de Chile [...] (Enciclopedia metódica, 1788b: 297).

HuEQUE, (el) de Chile es el Chilihueque, vease Lame (el) de Chile [...] (Enciclopedia metódica, 1788b: 297).

MUCA MUCA, en varios parages de América es el didelfo (Enciclopedia metódica, 1788b: 297).

REHUEQUE (el) de los Araucanos es el Chilihueque (Enciclopedia metódica, 1788b: 297).

Se trata de denominaciones de animales de América que no se conocían en Europa y consecuentemente no aparecieron en la Enciclopedia francesa. En casi todos los casos la definición empieza por una comparación a un animal europeo y se mencionan las características que distinguen el animal denominado de éste. Solo chinchimén, chingue, colocolo y cuy fueron aceptados por la Real Academia, mientras que las otras palabras no entraron en su Diccionario. En este caso se trata de adiciones de palabras y además de cosas que se descubrieron y necesitaban una denominación en español. 
Los traductores necesitaban conocimientos enciclopédicos para actualizar los artículos de la Enciclopedia metódica y también para adaptarlos a la realidad española. Se han añadido algunos artículos sobre artes particulares de España, cuyos utensilios no se conocen en los demás países. Así es, que los oficios de Alpargatero, de Esterero de esparto, de Esterero de palma, etc. y otros de España, que no se usan en Francia, forman artículos nuevos que se han insertado en sus lugares respectivos o por vía de suplemento.

Las materias de todas las telas, los tejidos de toda especie y el progreso de todo el arte que le es propio, ocupan el primer lugar de esta parte de la Enciclopedia Metódica; los cueros y pieles el segundo; el pintado y estampado de todos ellos el tercero; y el último los aceites y jabones.

Los artículos en la Enciclopedia Metódica siguen el orden alfabético en los volúmenes correspondientes a las temáticas, pero en algunos casos se introduce también el orden onomasiológico. Así, para las palabras que empiezan con la letra $c$, el volumen sobre Fabricas, Artes $y$ oficios, traducido por Angelio Carbonel, cuenta con los artículos siguientes (Enciclopedia metódica, 1794):

\author{
Cañamo \\ Cañon, canilla, roel, espolin, bobina, bolon y carrete \\ Carda, cardadura, cardero \\ Cardon, cardencha, palmar \\ Cerda, cepillo, pincel, brocha \\ Cinta \\ Cola \\ Comercio \\ Cordonero \\ Cuerda, cordel, cordeleria
}

En los artículos respectivos se mencionan también fábricas españolas, por ejemplo las fábricas de algodón de Madrid (Enciclopedia metódica, 1794: 17) y características de su producción. Se añaden también citas de documentos de las sociedades económicas y hay adiciones a algunos artículos que se basan en escritos de científicos españoles. Por ejemplo, en las adiciones al artículo Blanqueo se da un extracto de una Memoria de Pedro Gutiérrez Bueno (1745-1826), catedrático de química del Real Laboratorio de Madrid, leída el 31 de marzo de 1791, 
en la cual describe experiencias de blanqueo con óxido de manganeso (Enciclopedia metódica, 1794: 52-53). En algunos casos se citan leyes y ordenanzas, como por ejemplo las Ordenanzas del gremio de esparteros-estereros de Madrid.

\section{El traductor como innovador de la terminología}

Todas las piezas añadidas enseñan que esta parte de la Enciclopedia Metódica fue traducida para fomentar la industria en España. Pero el trabajo terminológico cuyo fin es el enriquecimiento de la lengua española y su adecuación a las exigencias del progreso científico y tecnológico no es menos importante. En este trabajo jugaba un gran papel la reflexión sobre los sinónimos al cual se atribuye una gran parte del Diccionario de gramatica y literatura (Enciclopedia metódica, 1788b). Al traductor le parece sobre todo importante añadir muchos artículos sobre los sinónimos castellanos (Enciclopedia metódica, 1788a: V). Constata la ausencia de descripciones de sinónimos castellanos, lo que no corresponde a la realidad. Se ignora toda la tradición de la descripción de sinónimos castellanos, como si las relaciones y las diferencias entre las palabras no hubieran interesado a los filólogos durante muchos siglos. La negación de una tradición española puede servir de justificación de nuevos trabajos en el ámbito pretendidamente descuidado. Para la descripción de los sinónimos utilizó la obra del Abate Pierre Joseph André Roubaud (1730-1792), en la que aumenta, corrige y rectifica muchos artículos de Gabriel Girard (1677-1748) y de Diderot de la Enciclopedia francesa.

Los traductores de la Enciclopedia metódica se entendían como innovadores de la terminología española. Pero la traducción de un Diccionario de sinónimos no es un trabajo mecánico. El traductor Mínguez lo reconoce y procede a una especie de sinonimia contrastiva. En la descripción de los sinónimos no le ayudan las etimologías de las palabras de las cuales se había servido Roubaud. Mínguez se queja de este trabajo en el prefacio:

En dar y fixar á las voces francesas las correspondencias Castellanas, no hemos dexado de tener algunas veces bastante trabajo, porque suelen distar mucho unas de otras y por habernos propuesto seguir el methodo de Mr. Roubaud, que pone la etimologia de casi todas las palabras de su 
lengua, que de ningun modo quadra ni conviene á los nuestras Castellanas (Enciclopedia metódica, 1788a: V).

La traducción literal del texto francés resulta imposible, incluso los ejemplos "traducidos fielmente no dicen bien con la doctrina que alli se asienta" (Enciclopedia metódica, 1788a: V). Así, ha sido preciso substituir o añadir otros ejemplos castellanos que corresponden a los mismos preceptos y reglas. No es solamente para subrayar la dificultad de este trabajo cuando el traductor expresa sus dudas sobre la calidad terminológica de las palabras en el ámbito en cuestión.

Hay otros casos que son testimonios de una carencia de palabras en español que ya existían en francés. Así, por ejemplo, el traductor del tomo de Ornitología de la Enciclopedia metódica se queja de la falta de diccionarios españoles de Ornitología, y además "los pocos Autores que han tratado de ella en general, ó por mejor decir ninguno, y la confusión que se halla en los Autores extranjeros, aplicando un mismo nombre á tres aves distintas de las de entre nosotros, y á veces describiendo una misma, bien que con nombre diverso, en dos parages diferentes" (Enciclopedia metódica, 1788b: prólogo). Para elaborar un diccionario de ornitología en español procuraron valerse de todos los medios posibles, ya acudiendo a diccionarios latinos, italianos, franceses y españoles, ya leyendo y cotejando las obras de Buffon, de Brisson y de otros autores, y ya comparando las descripciones francesas con las españolas, para asegurarse en la aplicación de los nombres.

En los dos tomos sobre Fabricas, Artes y oficios, traducidos del francés al castellano por Angelio Carbonel se subraya la utilidad de "esta grande masa de los conocimientos humanos, no menos esencial, si no tan brillante, que la de las ciencias mas sublimes, al bien de la Sociedad civil, y seguramente la mas útil á sus individuos después de la Agricultura" (Enciclopedia metódica, 1794: Aviso del editor). También en este ámbito es preciso un trabajo sobre la lengua, lo que reconoce el editor con las palabras siguientes:

Entre nuestros Españoles, que no han dedicado sus plumas y sus observaciones á la descripción y enseñanza de las artes mecánicas, es mas desconocido, misterioso, y recatado el idioma de ellas; retraído anda en los talleres y oficinas, y allí lo ha de buscar el sabio, para trasladarlo á los Diccionarios técnicos y facultativos, como lo han hecho los extranjeros (Enciclopedia metódica, 1794: Aviso del editor). 
La lengua francesa, muy rica en este ramo, no podía servir de auxilio para verter la definición y el significado de los nombres solo con acomodar la terminación o la ortografía de las voces al uso español, como sucedía con las de guerra, de jurisprudencia, de matemática, de física, y de política.

En la redacción de la traducción española de los artículos sobre Fabricas, Artes y oficios el traductor se encontró con las dificultades siguientes: Tenía que buscar expresiones en lengua escrita que nunca habían sido utilizado en textos escritos, sino que se utilizaban solamente en el lenguaje hablado de los artesanos. Además, los maestros, los fabricantes, como conjurados contra la Ilustración, han mostrado tanto recato y tanta repugnancia al comunicar los términos técnicos de sus utensilios, de sus operaciones, y de los mismos artefactos, que más de una vez se han desesperado los traductores ante la dificultad de encontrar las palabras populares de los distintos utensilios.

En vez que, en el caso de estas ciencias aplicadas, se tratara de inventar nuevos términos sobre la base de palabras ya existentes en el lenguaje corriente, había otros casos en los cuales los traductores se encontraban frente a textos originales escritos en un lenguaje completamente innovador. Un ejemplo de tal tarea es la traducción de la obra del Tratado elemental de Química de Antoine Laurent de Lavoisier (17431794, cf. Garriga Escribano, 1996: 197). El 18 de abril 1787 Lavoisier presentó a la Academia Real de las Ciencias de París una Memoria sobre la necesidad de perfeccionar y reformar la nomenclatura de la quimica, resultado de un trabajo común con los químicos Louis-Bernard Guyton de Morveau (1737-1816), Claude Louis Berthollet (1748-1822) y Antoine-François Fourcroy (1755-1809). Morveau, encargado de componer la parte química de la Enciclopedia Metódica, había elaborado en 1782 una tabla cuyo principio general consistía en que el nombre de la sustancia indicase su composición química. En su Memoria, Lavoisier subraya la función cognitiva de la lengua, y en particular de la nomenclatura de una ciencia que tiene que ser un método analítico que nos ayude a proceder de lo conocido a lo desconocido:

Las lenguas no solo tienen por objeto, como se cree comúnmente, expresar por signos las ideas y las imágenes; sino que además son verdaderos métodos analíticos, con cuyo auxilio procedemos de lo conocido á lo desconocido, y hasta cierto punto, al modo de los matemáticos [...] (Morveau, Lavoisier, Bertholet, Fourcroy / Gutiérrez Bueno, 1788: 4). 
Solo un año después de que apareciera el original, el profesor de química del Real Laboratorio de Madrid, Pedro Gutiérrez Bueno, publicó la traducción al castellano de esta obra divulgadora ${ }^{1}$. Esta traducción de la Nomenclatura fue sin duda "la más importante para la divulgación de la nueva química en España" (Garriga Escribano, 1997: 35). En los diez años que seguían aparecieron en español los principales tratados de los químicos franceses: las Lecciones de química teórica y práctica de Morveau, Maret y Durande (1789), los Elementos de química de Jean-Antoine Chaptal (1793-94), los Elementos de Historia Natural y de Química de Fourcroy (1793-95), el Arte de fabricar el salino y la potasa de Lavoisier (1795), los Elementos del arte de teñir de Berthollet (1795), y la obra el Tratado elemental de química (1798) de Lavoisier.

La idea de la lengua que funciona como un método analítico para la ciencia es retomada por Lavoisier en el discurso preliminar a su Traité élémentaire de chimie, publicado en 1789, siendo una de las obras más importantes de la historia de la química. El objetivo de este tratado no era la enseñanza de la química como se conocía hasta entonces, sino la presentación de la teoría combinatoria de la química a base de treinta y tres elementos o sustancias cuyas denominaciones aparecen en la tabla siguiente:

\footnotetext{
${ }^{1}$ Sobre las traducciones de la Nomenclatura de la química al español, cf. Garriga Escribano (1997). Lépinette (1996) presenta el panorama de la traductología en España en el siglo XVIII y también las consecuencias que las traducciones tienen en la configuración del vocabulario técnico español.
} 
192 DES SUBSTANCES SIMPLES.

TABLEAU DES SUBSTANCES STMPLES:

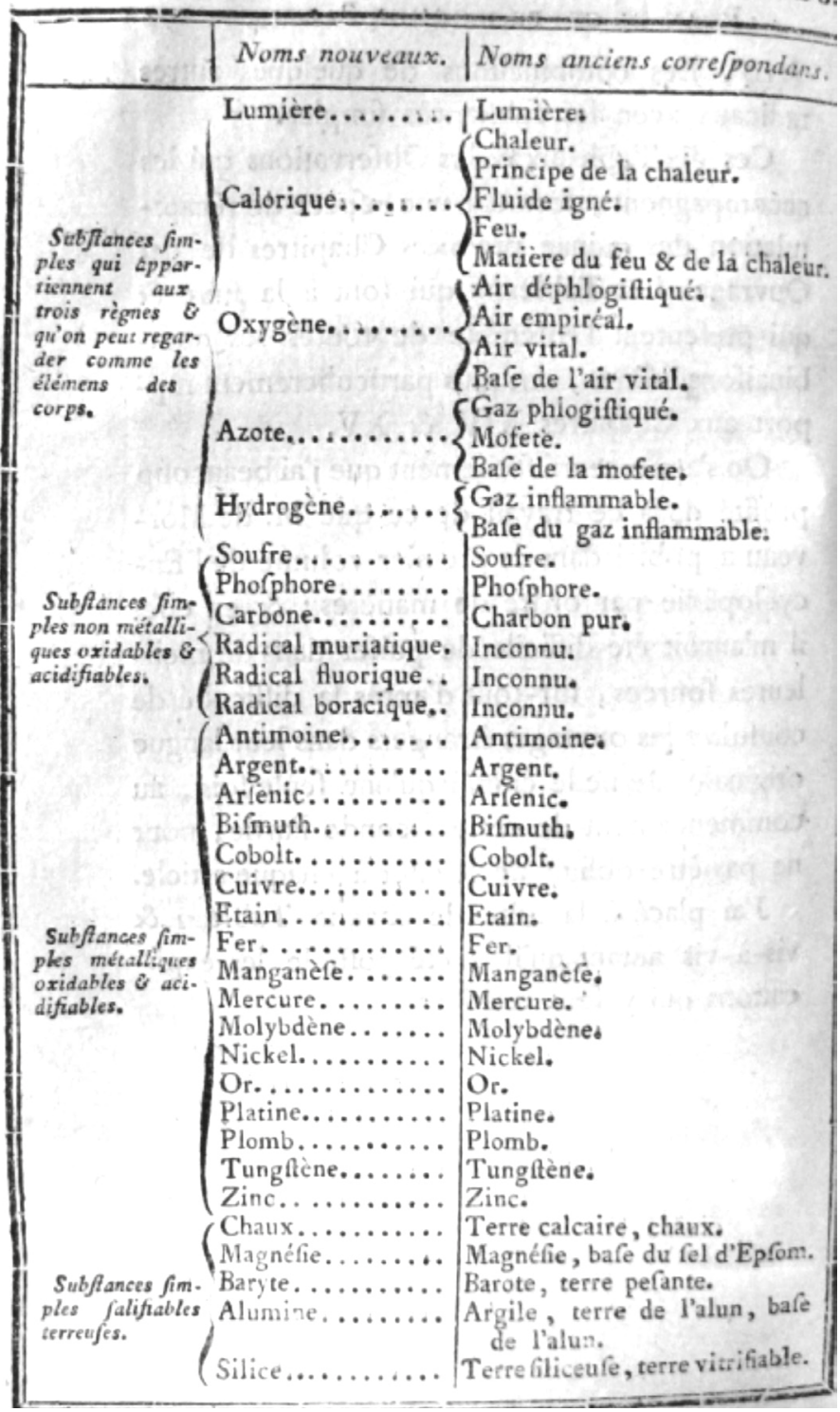

(Lavoisier, 1989: I, 192) 
En esta tabla se encuentran elementos que un químico de hoy en día reconocería (oxígeno, hidrógeno, azufre, fósforo) y los metales, mientras que a la luz y al calórico no se concede este estatus de elementos. Lavoisier elabora un enfoque combinatorio en el cual los compuestos químicos se consideran como un campo geométrico donde el compuesto se reconoce a partir de las denominaciones de sus partes. Distingue los compuestos según el grado de oxigenación:

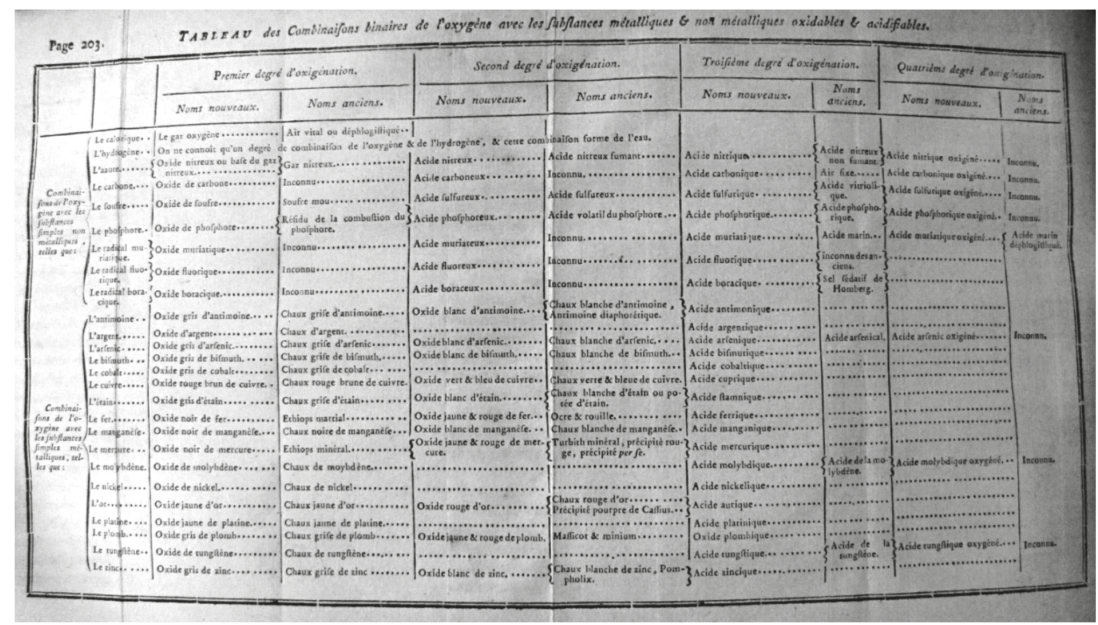

(Lavoisier, 1789: I, 203)

Cuando miramos la línea del ferro, encontramos oxide noir de fer para el primer grado de oxigenación y oxide jaune \& rouge de fer para el segundo, mientras que las antiguas denominaciones no eran transparentes: ethiops martial respectivamente ocre \& rouille. Las nuevas denominaciones seguían el principio de la analogía, eso quiere decir que en todos los casos que aparece una palabra, por ejemplo oxide, tiene el mismo significado, en este caso 'compuesto de oxígeno', y cuando se trata de cierto significado siempre tiene que utilizarse la misma palabra.

Ya en la traducción de la Memoria sobre la necesidad de perfeccionar y reformar la nomenclatura de la química, Pedro Gutiérrez Bueno parte de la escasez de voces que padece la lengua española en cuestión de ciencias naturales y artes (Morveau, Lavoisier, Bertholet, Fourcroy / Gutiérrez Bueno, 1788: III), pero su intento no era añadir 
estas voces al idioma español, sino "mejorar y reformar el lenguage de la química, y hacerle por este medio comun á todos los Países, y facilitar la comunicacion de los trabajos de los Profesores y Aficionados á esta utilisima ciencia" (Morveau, Lavoisier, Bertholet, Fourcroy / Gutiérrez Bueno, 1788: IV). Por esta razón Gutiérrez Bueno decidió adoptar la voz según se hallaba en el original o darle la menor mutación que fuese posible para no desfigurarla. Cuando parecía conveniente, se dejaban las voces originales con los mismos caracteres que estaban escritas, diciendo acetate, acetite, baryte, molybdate, nitrate, nitrite, etc. Para denominar el nitrógeno se introdujo una segunda o (fr. azote, esp. azoote). Azoote expresa la calidad de ser no-vital en vez que azote significa en español 'un flagelo' o con su significado metafórico 'una calamidad pública'. Cuando la voz francesa no hacía un buen sonido, se la aproximaba a la voz latina. Por ejemplo, la palabra francesa sulphure se ha substituido por sulfurete, que tiene más analogía con la palabra latina sulphuretum. Para denominar las composiciones jabonosas compuestas con aceites volátiles se ha introducido la palabra xaboncillo, que no se parece al original, pero está apoyado por la analogía entre sapo en latín, savon en francés y jabón en español y sus diminutivos saponulus, savonule, xaboncillo.

El traductor del Tratado elemental de química, Juan Manuel Munárriz (1761-1731), capitán del Real Cuerpo de Artillería y profesor de matemática en su Academia, dice en una advertencia que ha "procurado seguir con todo rigor la nueva nomenclatura química, que es la misma que se halla en el tomo segundo de la traducción de los Elementos del Arte de Teñir del célebre Berthollet" (Lavoisier / Munárriz, 1798: Advertencia).

Para las sustancias simples ha seguido la nueva terminología. En la mayoría de los casos, la innovación en relación con los nombres antiguos correspondientes se limita a una unificación: 


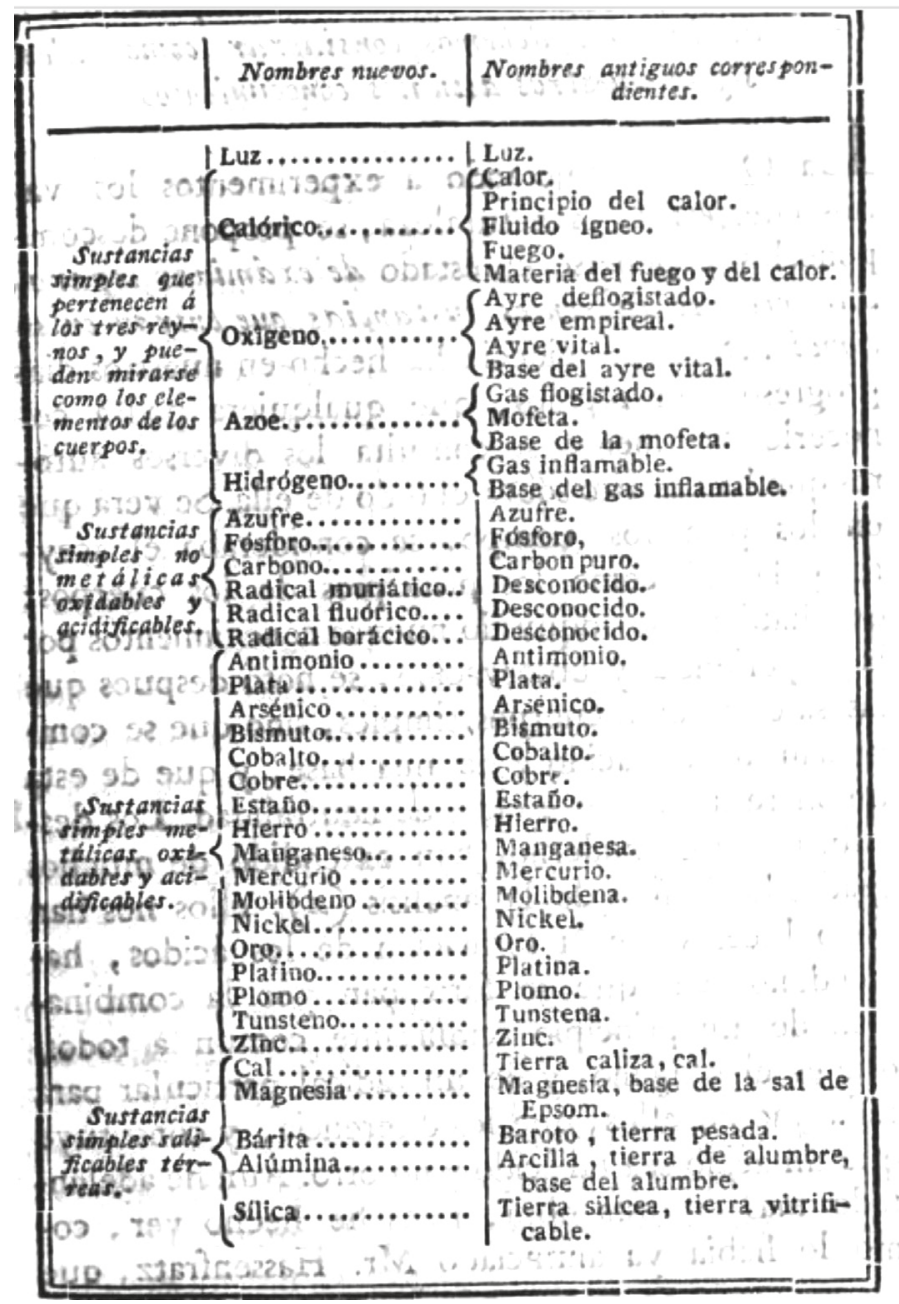

(Lavoisier / Munárriz, 1798: I, 135)

En la discusión sobre la nomenclatura de las diferentes partes constitutivas del aire de la atmósfera se constatan lagunas semánticas en la denominación de estados físicos. Lavoisier había deplorado la carencia de conocimientos sobre las propiedades químicas de las partes no respirables del aire de la atmósfera y había decidido deducir el nombre de su base de la propiedad que tiene este gas para quitar la vida a los animales que lo respiran: 
[...] nous l'avons donc nommé azote, de l'a privatif des Grecs, \& de

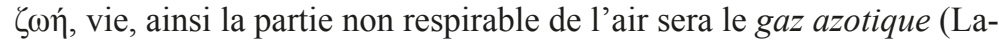
voisier, 1789: 55).

Munárriz optó por el término azoe, que corresponde literalmente al griego, y utiliza la misma forma para el adjetivo.

[...] así le llamamos azoe compuesto de la $\alpha$ privativa de los Griegos,

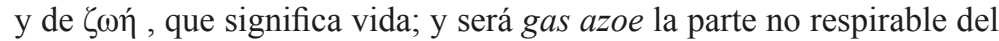
ayre (Lavoisier / Munárriz, 1798: I, 38).

Munárriz eligió para la traducción de la obra de Lavoisier la nomenclatura que García Fernández había añadido a los elementos de Berthollet (1795) y que no presentaba grandes diferencias respecto a la traducción que había realizado Gutiérrez Bueno (cf. Garriga Escribano, 1997), aunque tiene no solo en cuenta la analogía con la lengua francesa, sino también con la latina y la griega.

En el uso de la derivación para formar nuevas palabras Munárriz es más retentivo que Lavoisier, quien utiliza las palabras acides, acidité, acidifiée, acidifiable, acidifiant en un párrafo:

Les trois exemples, d'ailleurs, que je viens de citer, suffisent pour donner une idée claire \& précise de la manière dont se forment les acides. On voit que l'oxigène est un principe commun à tous, \& que c'est lui qui constitue leur acidité; qu'ils sont ensuite différenciés les uns des autres par la nature de la substance acidifiée. Il faut donc distinguer, dans tout acide, la base acidifiable, à laquelle M. de Morveau a donné le nom de radical, \& le principe acidifiant, c'est-à-dire l'oxygène (Lavoisier, 1789: 69).

De la palabra acide Lavoisier había formado cinco palabras por sufijos: el sufijo -ité significa la calidad, -ifier el verbo del cual se deriva por ifié(e), la denominación de la sustancia que está sujeto al proceso denominado por el verbo, -able la sustancia que es capaz de estar sujeto al proceso y -ifiant la sustancia que produce el proceso.

Para la mayoría de estas palabras Munárriz creó neologismos análogos, pero para la propiedad misma prefería la denominación propiedad ácida, probablemente porque la palabra acidia (acedía) ya existía en la lengua común con el significado 'pereza, flojedad'. La palabra acidez 
está integrada en el Diccionario de la Real Academia desde el año 1817 (RAE, 1817: 12) con el significado ‘la calidad de ácido’ y la etimología aciditas:

[...] los tres ejemplos citados bastan para dar una idea clara y precisa del modo cómo se forman dichos ácidos. Se ve que el oxigeno es un principio comun á todos ellos, y el que constituye su propiedad ácida, $\mathrm{y}$ que se diferencian unos de otros por la naturaleza de la sustancia acidificada, de modo que en todo ácido se debe distinguir la base acidificable, á la qual Morveau ha dado el nombre de radical, y el principio acidificante, esto es, el oxígeno (Lavoisier / Munárriz, 1798: I, 48).

Resumimos la discusión sobre la derivación a partir del término francés acide y de la palabra castellana sustantivada ácido en la tabla siguiente. Presenta mucha analogía, salvo la denominación compleja propiedad ácida:

\begin{tabular}{|l|l|l|l|l|}
\hline $\begin{array}{l}\text { denominación } \\
\text { francesa }\end{array}$ & sufijo & $\begin{array}{l}\text { significado } \\
\text { del sufijo }\end{array}$ & $\begin{array}{l}\text { denominación } \\
\text { castellana }\end{array}$ & $\begin{array}{l}\text { Sufijo cas- } \\
\text { tellano }\end{array}$ \\
\hline acides & - & - & ácidos & - \\
\hline acidité & -ité & calidad & $\begin{array}{l}\text { propiedad } \\
\text { ácida }\end{array}$ & $\begin{array}{l}\text { denomina- } \\
\text { ción com- } \\
\text { pleja }\end{array}$ \\
\hline acidifier & -ifier & $\begin{array}{l}\text { proceso de- } \\
\text { nominado } \\
\text { por el verbo }\end{array}$ & acidifica & -ificar \\
\hline acidifiée & $e ́(e)$ & $\begin{array}{l}\text { sustancia que } \\
\text { está sujeto al } \\
\text { proceso }\end{array}$ & acidificada & -ada \\
\hline acidifiable & -able & $\begin{array}{l}\text { sustancia que } \\
\text { es capaz de } \\
\text { estar sujeto } \\
\text { al proceso }\end{array}$ & acidificable & -able \\
\hline acidifiant & -ant & $\begin{array}{l}\text { la sustancia } \\
\text { que produce } \\
\text { el proceso }\end{array}$ & acidificante & -ante \\
\hline
\end{tabular}


Para subrayar la composición con el oxígeno, Lavoisier había introducido un hiperónimo para el verbo acidifier, oxygéner, del cual derivó el substantivo oxygénation:

Nous nommerons donc oxygénation la conversion du phosphore en un acide, \& en général la combinaison d'un corps combustible quelconque avec l'oxygène. Nous adopterons également l'expression d'oxygéner, $\&$ je dirai en conséquence qu'en oxygénant le phosphore, on le convertit en un acide (Lavoisier, 1789: 65-66).

Munárriz sigue esta manera de denominación de Lavoisier y crea los términos oxigenacion y oxigenar, pero se limita al infinitivo y no presenta, como tampoco lo hace Lavoisier, la derivación del participio. Esta frase (je dirai en conséquence qu'en oxygénant le phosphore) es similar a un ejercicio lingüístico que introduce la formación del participio. En el Diccionario de la Real Academia oxigenar ya aparece por primera vez en 1817, pero oxigenación solamente en 1927 (RAE, 1927: 1404).

[...] llamaremos oxigenacion la conversión del fósforo en un ácido, y generalmente hablando la combinación de cualquiera cuerpo combustible con el oxígeno. Igualmente adoptaremos la expresión de oxigenar; y diremos que oxigenar el fósforo es convertirlo en un ácido. (Lavoisier / Munárriz, 1798: I, 46)

Se sigue usando esta manera muy análoga de construcción también en la denominación de las sustancias compuestas. Antes de dar las informaciones sobre sus experimentos y las tablas con las denominaciones nuevas y antiguas, Lavoisier había afirmado que

[...] el mérito de la nomenclatura que hemos adoptado consiste principalmente en que nombrada la sustancia simple, se deduce necesariamente de esta primera palabra el nombre de todos sus compuestos (Lavoisier / Munárriz, 1798: I, 46. Cf. Lavoisier, 1789: 56).

La analogía, según la cual un elemento que aparece en un compuesto se denomina siempre con el mismo término, permite, por ejemplo, la clasificación de todas las combinaciones del ácido sulfúrico como 
sulfates. El término francés sulfate está transpuesto literalmente al español:

238 COMBINAISONS DE

$T A B L E A V$ des combinaifons de $P$ Acide fulfurique ?

affinité avec cet actide

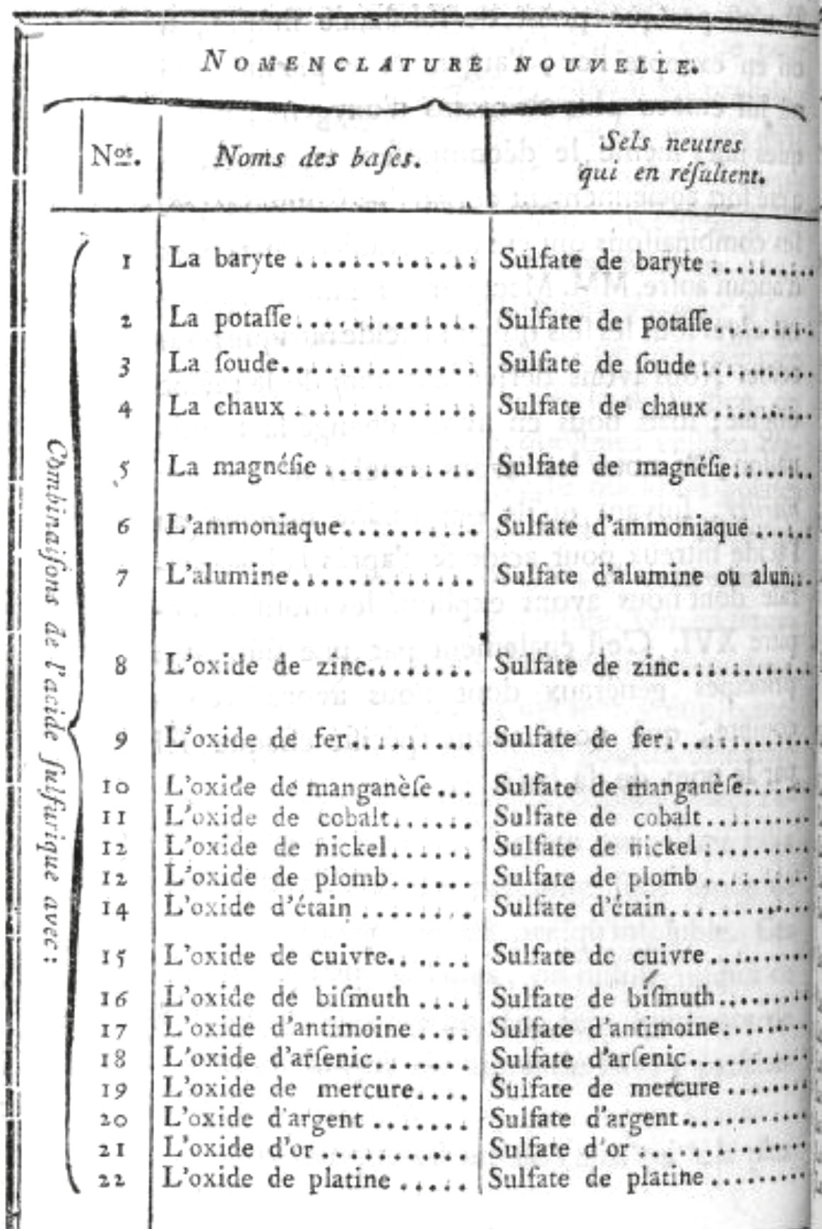

(Lavoisier, 1789: 238) 


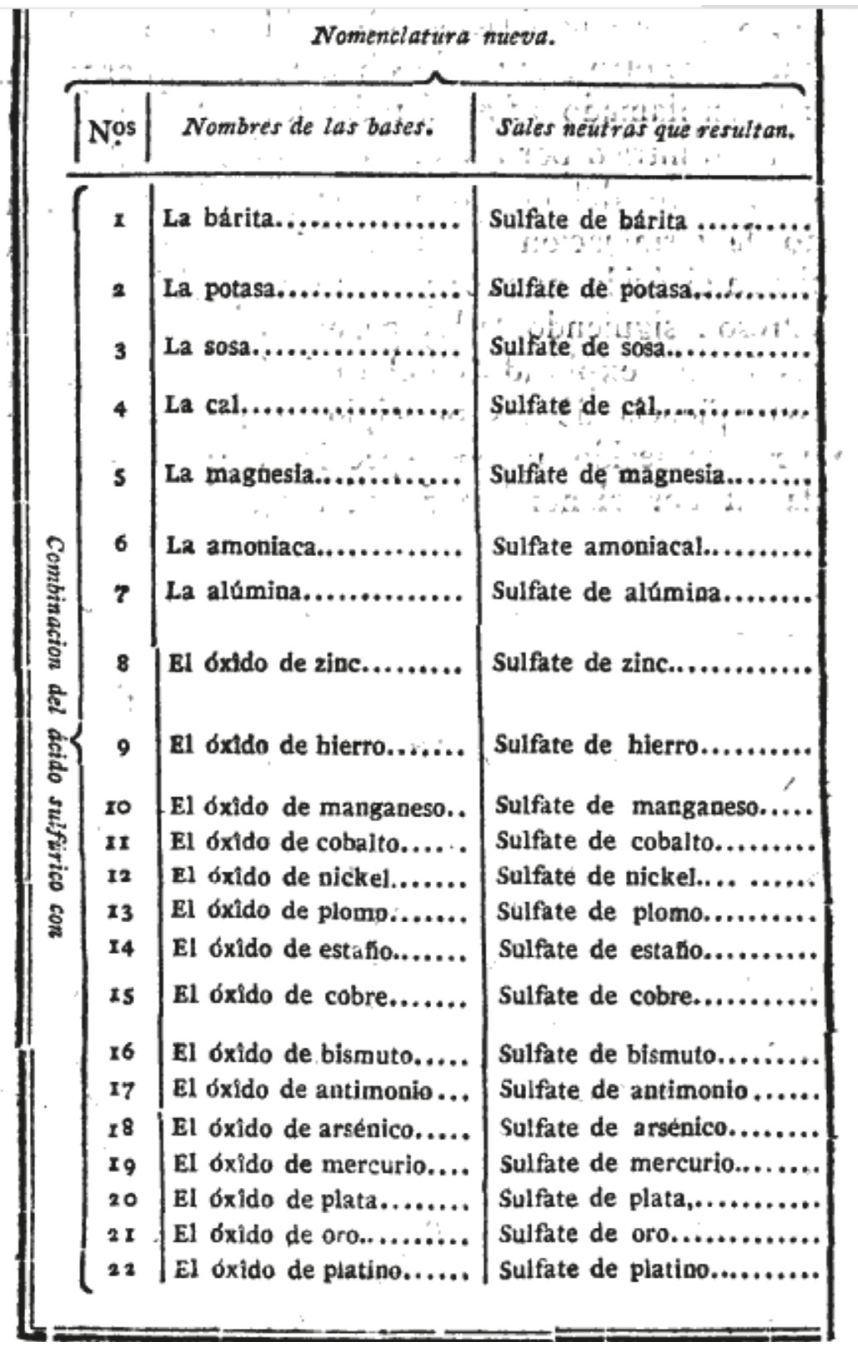

(Lavoisier / Munárriz,1798: I, 46. Cf. Lavoisier, 1789: 174)

Esta denominación completamente análoga que es transparente en cuanto a las partes del compuesto no era posible con la nomenclatura antigua: 


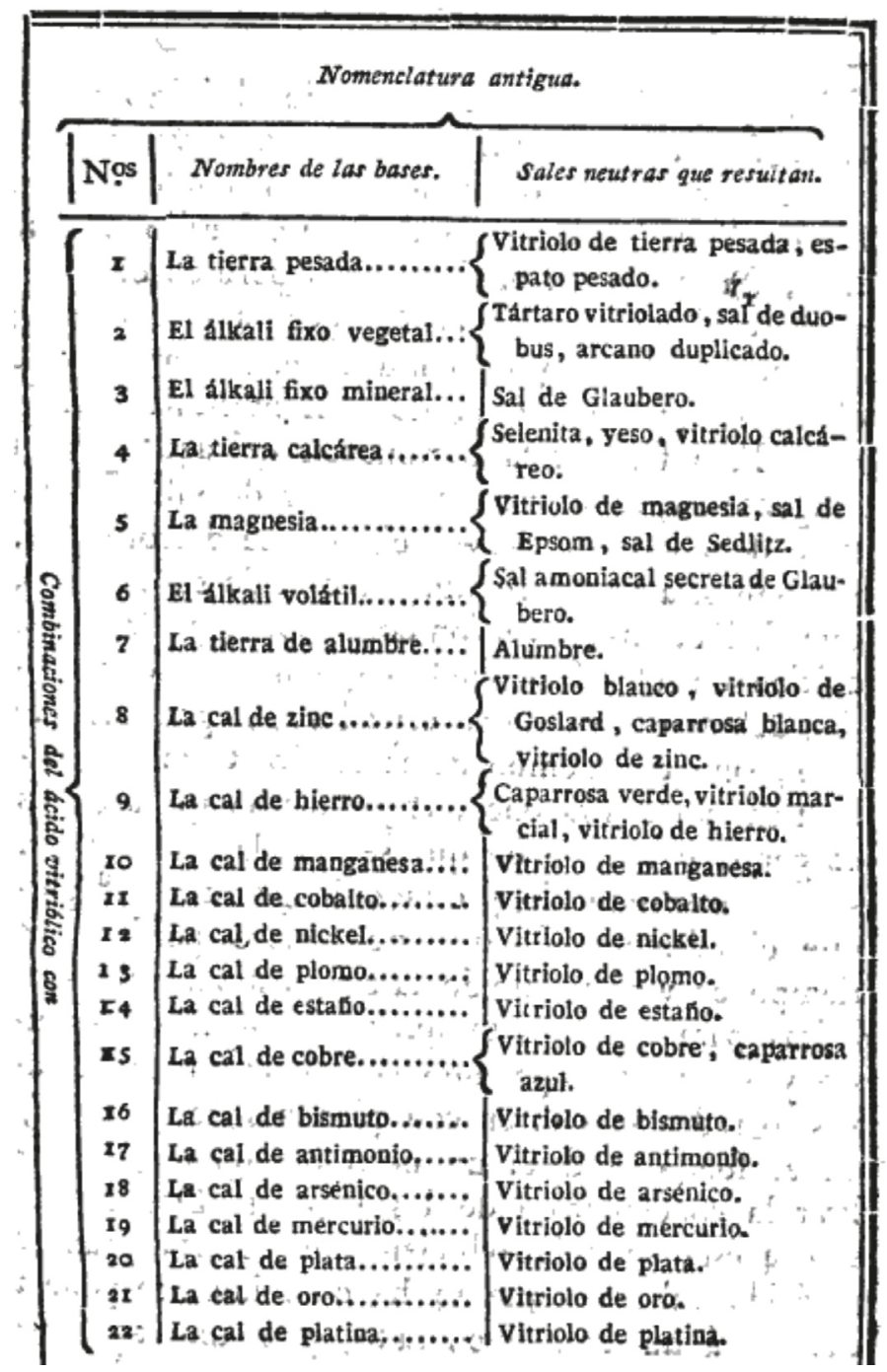

(Lavoisier / Munárriz, 1798: I, 46. Cf. Lavoisier, 1789: 175)

Parece que su trabajo como químico y traductor fortaleció a Munárriz para utilizar la nueva terminología. Munárriz publicó también un Suplemento á la traducción castellana de los elementos de química de J. A. Chaptal donde escribe: 
Últimamente, para observar la posible uniformidad de la traduccion, hemos procurado seguir literalmente la misma nomenclatura, aunque nos hayamos á veces separado de ella en otra obra de Química que hemos traducido á nuestra lengua (Munárriz, 1801: 4).

\section{El traductor en el proceso de mediación y adaptación}

Ya hemos observado la necesidad de adaptar textos originales a la realidad española y al público español. Los traductores utilizaron varios recursos para realizar esta adaptación. El más simple parece ser la transposición de los hechos descritos a España. De esta manera procedió Juan Sempere y Guarinos (1755-1830) en su traducción de las Riflessioni sul buon gusto de Ludovico Antonio Muratori (1672-1750) (cf. Froldi, 1999: 191-193). Cuando Muratori afirma que Italia no se ha visto implicada en la peste de la herejía protestante, el traductor Sempere sustituye Italia con nosotros, refiriéndose claramente a España (Lamindo Pritanio [Muratori], 1715: 13; Sempere, 1782: 9).

Sempere procede a hacer otra adaptación, creyendo oportuno saltar un pasaje en el cual Muratori cita a Giovanni Pico della Mirandola (1463-1494), que privó a los españoles del genio filosófico, juzgando que

Avicenna, Averroè, Albumazar e tutti gli scrittori che in Africa e in Ispagna una volta furono celebri nelle scienze, non avessero ingegno filosofico se non perché a sangue freddo spacciavano tante favole e bugie (Lamindo Pritano, 1715 [Muratori]: 39; Sempere, 1782: 32).

El recurso de traducción de Sempere es un claro ejemplo de corrección de la idea original, en la cual el traductor procede a una adaptación del texto original al lector español. Se puede apreciar en Sempere la tendencia a una extrema concisión que obtiene abreviando el texto, eliminando todo aquello que considera superfluo y sintetizando todo aquello que Muratori ha expuesto con una mayor riqueza de argumentos.

Este trabajo de adaptación llevado a cabo por los traductores era aún más importante cuando hechos ideológicos, religiosos y morales o costumbres profundamente arraigadas iban en contra de la recepción inmediata del texto original. Este es el caso de un texto que se puede considerar como literario, pero sobre todo educativo: la Pamela, or 
Virtue Rewarded (1740) de Thomas Richardson (1689-1761), cuya traducción española apareció en 1794 bajo el título Pamela Andrews, ó la virtud premiada. Citamos según la segunda edición de 1799, en la cual el traductor cambia virtud "recompensada" por "premiada" (cf. Carnero, 2008: 102).

Richardson describe la "virtud" tal como era concebida en el siglo XVIII, ajena a nuestros tiempos. Pamela Andrews es una joven sirvienta en una casa adinerada. El hijo de la casa se apasiona por ella y trama diversas intrigas, con la ayuda de sus sirvientes, para poder obtenerla. Ella consigue triunfar en la protección de su virtud. El fulano, después de leer el diario que Pamela ha escrito en secreto, se ve forzado a proponerle matrimonio para obtenerla. La popularidad de Pamela se debió principalmente a la efectiva técnica de revelar la historia directamente por la protagonista, primero a través de cartas, y después, por su diario.

En el prólogo, el traductor Ignacio García Malo (1760-1812) subraya la mediación entre la cultura inglesa y la cultura española como objetivo de su traducción:

He aquí el objeto de nuestra traducción: presentar al público un modelo de modestia y de virtud á toda prueba. Este mismo ha sido el del autor; pero ó sea porque las costumbres de Inglaterra estan mas corrompidas que las nuestras, ó porque la índole de la lengua inglesa admite ciertas expresiones é idiotismos que sonarian mal en la nuestra, hemos juzgado oportuno reformarlas ó suprimirlas, sin que por esto falte nada á la accion principal, ó al fondo de la historia, [...] Que esto se diga ó no con las mismas expresiones del autor, y aun con los mismos episodios, importa poco para la moralidad que se pretende sacar, y que es y debe ser comun á todos los paises de la tierra. Por consiguiente seria mucha lástima que careciésemos de esta historia en nuestro idioma, por no reformar en el original las cosas accidentales que se oponen á nuestras costumbres y modo de pensar. Siempre que una mano diestra sepa separar lo perjudicial de lo útil en cualquiera obra extrangera, hará un servicio importante á las buenas costumbres y á las letras. Si Don Tomas de Iriarte no hubiera tenido presente esta máxima, propia de todo buen ciudadano, carecería la juventud española de la excelente historia del nuevo Robinson (Richardson, 1799: I, p. II).

García Malo fue secretario de un cardenal, empleado de la Real Biblioteca y amigo de Leandro Fernández de Moratín (1760-1828), Juan 
Pablo Forner (1756-1797) y Manuel José Quintana (1772-1857). Fue nombrado caballero de la orden de Carlos III en 1800 y comisario de guerra en 1806. Al sobrevenir la invasión francesa se unió a la resistencia nacional y fue oficial segundo de la Secretaría de la Junta Central desde enero de 1809 hasta su disolución. Pasó a Mallorca a mediados de 1810, donde desempeñó la Intendencia del ejército de Baleares (cf. Carnero, 1996). García Malo ocupa un lugar relevante en la historia española de la traducción por sus versiones de Homero y de Samuel Richardson. Sin embargo, el nombre del traductor no se menciona en la tapa de la obra traducida al español. Además de reformar en el original las cosas accidentales que se oponen a nuestras costumbres y modo de pensar, García Malo confiesa haber suprimido algún episodio escabroso y haber moderado el lenguaje para obviar asperezas morales. En todos los volúmenes hay notas léxicas para legitimar o aclarar la traducción de ciertos términos, o para ofrecer excursos literarios o puntualizaciones sobre geografía o costumbres inglesas. La nota de pág. 102 del vol. II se refiere a lo reprobable que es el suicidio.

Una lectura de los títulos de obras traducidas permite reconocer una gran variedad de realizaciones en la función de mediador. La traducción del siglo XVIII se presenta particularmente polimorfa, en razón tanto de la diversidad de criterios sobre la especie de tarea que el traductor debía imponerse, como de la misma heterogeneidad de sus objetivos (Urzainqui, 1991: 623). Inmaculada Urzainqui (1991: 623) ha descrito los modos de traducción en el siglo XVIII con doce nociones: restitución, selección, abreviación, acumulación, corrección, nacionalización, generalización, actualización, recreación, traducción, paráfrasis, continuación. Estos procesos de traducción se explican sobre todo por medio de textos literarios, pero se puede constatar que aparecen también en la traducción de textos no literarios.

Con su actividad de traducción en la cual utilizan diferentes modos, los traductores contribuyeron a la difusión del saber enciclopédico, aportaron innovaciones terminológicas y textuales y fueron mediadores entre culturas.

\section{Bibliografía}

Abellán, José Luis. 1981. Historia crítica del pensamiento español III: Del Barroco a la ilustración. Madrid: Espasa-Calpe. 
Carnero, Guillermo. 1996. Datos para la biografía del novelista dieciochesco Ignacio García Malo (1760-1812). Hispanic review 1: 1-18.

Carnero, Guillermo. 2008. Ignacio García Malo (1760-1812) y su actividad de traductor. Alicante: Universidad, Departamento de Literatura Española, 275-289. Alicante: Biblioteca Virtual Miguel de Cervantes. http:// www.cervantesvirtual.com/obra/ignacio-garca-malo-17601812-y-suactividad-de-traductor-0/ [Acceso 19/09/2015].

Ceballos, Fernando. 1774-76. La falsa filosofia o el ateismo, deismo, materialismo, y demas nuevas sectas convencidas de crimen de estado contra los soberanos, y su Regalias, contra los Magistrados, y Potestades legitimas. Madrid: Antonio Sancha.

Condillac, Etienne Bonnot de. 1784a. La lógica, o los primeros elementos del arte de pensar [...], traducida por D. Bernardo Maria de Calzada. Madrid: Ibarra.

Condillac, Etienne Bonnot de. 1784b. Lecciones preliminares del curso de estudios, trad. por D. Lope Núñez de Peralveja. Madrid: s.n.

Condillac, Etienne Bonnot de. 1794. Lógica de Condillac, puesta en diálogo por D. Valentín de Foronda. Madrid: s.n.

Condillac, Etienne Bonnot de. 1805. La lengua de los cálculos. Trad. por la Marquesa de Espeja. Madrid: s.n.

Destutt de Tracy, Antoine Louis Claude. 1826. Elementos de ideología, incluidos en diez y ocho lecciones, e ilustrados con notas críticas, por el catedrático D. Mariano $\mathrm{S}^{* * *}$. Paris: Masson e hijo.

Diderot, Denis \& Alembert, Jean le Rond d' (ed.). 1751-1772. Encyclopédie, ou Dictionnaire raisonné des sciences, des arts et des métiers. Paris: Briasson/David/Le Breton/Durand.

Enciclopedia metódica. 1788a. Diccionaro de gramatica y literatura, traducida del frances al castellano por el R. P. Luis Miguel de S. Fernando del Orden de Escuelas Pias. Tomo primero. Madrid: Sancha.

Enciclopedia metódica. 1788b. Historia natural de los animales, traducida del frances al castellano por D. Gregorio Manuel Sanz y Charias. Tomo primero. Madrid: Sancha.

Enciclopedia metódica. 1791a. Artes academicos, traducidos del frances al castellano: a saber, el arte de la equitacion, por Don Baltasar de Irurzun, y el del Bayle, de Esgrima y de Nadar. Madrid: Sancha.

Enciclopedia metódica. 1791b. Arte militar, traducido del frances al castellano con algunas adicones por el teniente coloniel de infanteria Don Luis Castañon. Tomo primero. Madrid: Sancha.

Enciclopedia metódica. 1792a. Arte militar, traducido del frances al castellano con algunas adicones por el teniente colonel de infanteria Don Luis Castañon. Tomo segundo. Madrid: Sancha. 
Enciclopedia metódica. 1792b. Geografia moderna, traducida del frances al castellano por los señores Don Juan Arribas y Soria, y Don Julian de Velasco. Tomo primero, segundo, y tercero. Madrid: Sancha.

Enciclopedia metódica. 1794. Fabricas, Artes y oficios, traducidos del frances al castellano por Angelio Carbonel. Tomo primero y segundo. Madrid: Sancha.

Froldi, Rinaldo. 1999. Juan Sempere y Guarinos, traductor de las Riflessioni sul buon gusto de Ludovico Antonio Muratori. En Lafarga, Francisco (ed.) La traducción en España (1750-1830). Lengua, literatura, cultura. Lleida: Edicions de la Universitat de Lleida, 187-194.

Garriga Escribano, Cecilio. 1996. Apuntes sobre la incorporación del léxico de la química al español: la influencia de Lavoisier. Documents pour l'histoire du français langue étrangère ou seconde: L' «universalité» du français et sa présence dans la Péninsule Ibérique 18: 419-435.

Garriga Escribano, Cecilio. 1997. La recepción de la Nueva nomenclatura química en español. Grenzgänge 8: 33-48.

Herrero, Javier. [1971] 1973. Los origenes del pensamiento reaccionario español. Madrid: Editorial Cuadernos para el Diálogo.

Jovellanos, Gaspar Melchor de. 1963. Obras. Tomo XLVI. Madrid: EspasaCalpe.

Lafarga, Francisco (ed.). 1999. La traducción en España (1750-1830). Lengua, literatura, cultura. Lleida: Edicions de la Universitat de Lleida.

LamindoPritanio [Ludovico Antonio Muratori].1708. Riflessioni sopra il buon gusto intorno alle scienze e le arti. Venezia: Luigi Pavino.

LamindoPritanio [Ludovico Antonio Muratori]. 1715. Delle Riflessioni sopra il buon gusto nelle scienze e nelle arti. Parte $\mathrm{II}^{\mathrm{a}}$. Colonia [Nápoles]: Benedetto Marco Renaud.

Lavoisier, Antoine Laurent de. 1789. Traité élémentaire de chimie, présenté dans un ordre nouveau et d'après les découvertes modernes. Paris: Cuchet.

Lavoisier, Antoine Laurent de. 1798. Tratado elemental de química, presentado baxo nuevo órden y conforme a los descubrimientos modernos. Traducido al castellano por Juan Manuel de Munarriz. Madrid: Imprenta Real.

Lépinette, Brigitte. 1996. La traduction scientifique en Espagne au XVIIIe siècle. En Ballard, Michel (ed.) Europe et Traduction. Arras/Ottawa: Presses de l'Université/Artois Presses Université, 117-137

Maymò y Ribes, Joseph. 1758. Defensa del Barbadiño en obsequio de la verdad. Madrid: En la Oficina de Joachin Ibarra. 
Menéndez y Pelayo, Marcelino. 1963. Historia de los heterodoxos españoles [1880], vol. V. Madrid: Consejo Superior de Investigaciones Científicas.

Morveau, Louis-Bernard Guyton de; Lavoisier, Antoine Laurent de; Berthollet, Claude Louis \& Fourcroy, Antoine-François de. 1788. Método de la nueva nomenclatura química. Propuesto por M.M. de Morveau, Lavoisier, Bertholet, y de Fourcroy, a la Academia de Ciencias de Paris, y traducido al castellano por D. Pedro Gutiérrez Bueno, Profesor de química en el Real Laboratorio de Madrid, \&c. Madrid: Antonio de Sancha.

Richardson, Tomas. 1794-1795. Pamela Andrews o la virtud recompensada. Escrita en inglés por Thomas [sic] Richardson. Traducida al castellano, corregida y acomodada a nuestras costumbres por el traductor. Madrid: Antonio Espinosa.

Richardson, Tomas. 1799. Pamela Andrews, ó la virtud premiada. Escrita en inglés por Tomas Richardson. Traducida al castellano, corregida y acomodada a nuestras costumbres por el traductor. Segunda edición. Madrid: Imprenta Real.

Sempere y Guarinos, Juan. 1782. Discurso sobre el gusto actual de los españoles en la literatura. En Reflexiones sobre el buen gusto en las ciencias y en las artes. Madrid: Antonio de Sancha, 196-291.

Urzainqui, Inmaculada. 1991. Hacia una tipología de la traducción en el siglo XVIII: los horizontes del traductor. En Donaire, M. ${ }^{a}$ Luisa \& Lafarga, Francisco (eds) Traducción y adaptación cultural: España-Francia. Oviedo: Universidad de Oviedo, Servicio de Publicaciones, 623-638.

Verney, Luis Antonio. 1746. Verdadero método de estudar, para ser util à Republica, e à Igreja: proporcionado ao estile, e necesidade de Portugal. Valensa [Nápoles]: na oficina de Antonio Balle.

Verney, Luis Antonio. 1760. Verdadero método de estudiar para ser útil a la República y a la Iglesia, proporcionado al estilo, y necessidad de Portugal, [...]. Traducido al castellano por don Joseph Maymò y Ribes, Doctor en Sagrada Theologìa, y Leyes, Abogado de los Reales Consejos, y del Colegio. Madrid: Joachin Ibarra. 